\title{
The Use of Artificial Intelligence in Forest Product Manufacturing: A Low- cost Improvement in Competitiveness
}

\section{Fernández $\mathrm{FG}^{1^{*}}$ and Izquierdo $\mathrm{SI}^{2}$}

${ }^{1}$ Department of Systems and Natural Resources, Polytechnic University of Madrid, Spain

${ }^{2}$ MTP Digital Business Assurance, Madrid, Spain

"Corresponding author: Francisco García Fernández, Department of Systems and Natural Resources. Polytechnic University of Madrid, Spain, Tel: +34 636159244 ; E-mail: francisco.garcia@upm.es

Received date: January 07, 2016, Accepted date: January 09, 2016, Published date: January 10, 2016

Copyright: (c) 2016 Fernández FG. This is an open-access article distributed under the terms of the Creative Commons Attribution License, which permits unrestricted use, distribution, and reproduction in any medium, provided the original author and source are credited.

\section{Forest Product Manufacturing}

Quality control of wood-based products before they are placed in the market, require a series of costly tests which often include long ageing periods. This often forces manufacturers to maintain a stock of product immobilized for long periods, which in the case of structural wood-based panels can exceed a month (Figures 1 and 2) [1].

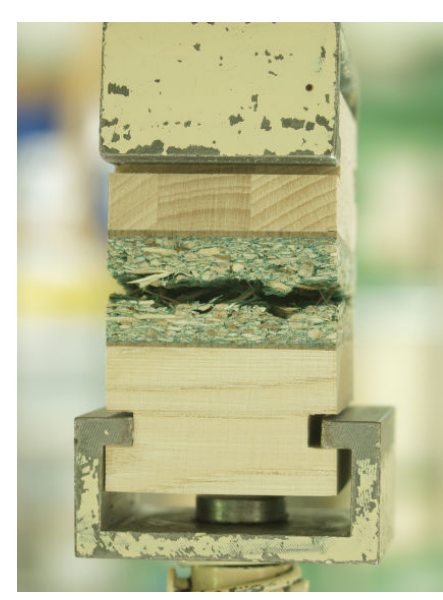

Figure 1: Tensile strength test after 21 days of immersion, freezing and drying (EN 321).

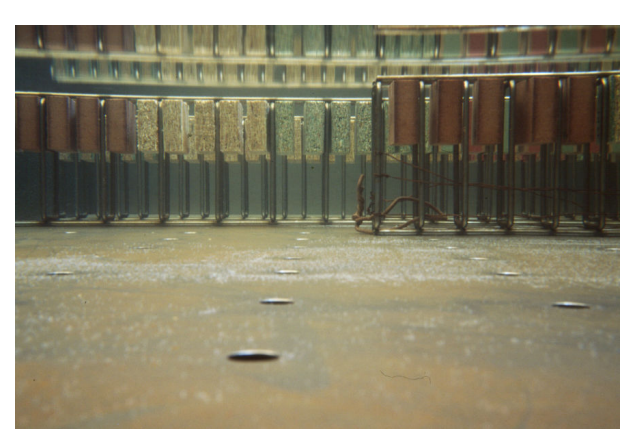

Figure 2: Swelling in thickness test after 24 hours of immersion in water (EN 317).

On the other hand, the wood product manufacturing industry is characterized by significant competition, high variability in customer's requirements, and the need to develop more and more price competitive products. These interrelated factors force manufacturers to continuously adjust, control and optimize their manufacturing parameters in order to develop products of higher quality that better fit the customer needs at a lower cost.

These characteristics of the industry make it very desirable to develop a high accuracy and reliable tool to obtain the final characteristics of a product by means of its manufacturing parameters, rather than testing after several weeks of manufacturing [2].

In this respect, artificial neural networks and fuzzy logic are a two promising tools based on artificial intelligence to improve the competiveness of forest product manufacturing companies. These new modeling and manufacturing control techniques allow companies to significantly increase their competitiveness by reducing manufacturing and testing times and costs without decreasing the reliability of the results.

These techniques can act as a realistic simulator of the production line itself, allowing adjusting manufacturing parameters to obtain a better product with lower costs.

Two of the main challenges of these techniques, and which for years prevented their industrial applications, have recently been solved (Figure 3). The first one was that these techniques act as a black box where it is impossible to know how variables relate to each other [3]. The second one is that neither technique provides the uncertainty or reliability of its results [4]. These two challenges can now be solved through Monte Carlo and Bootstrap simulation methods to provide manufacturers with a reliable optimization tool [5-8].

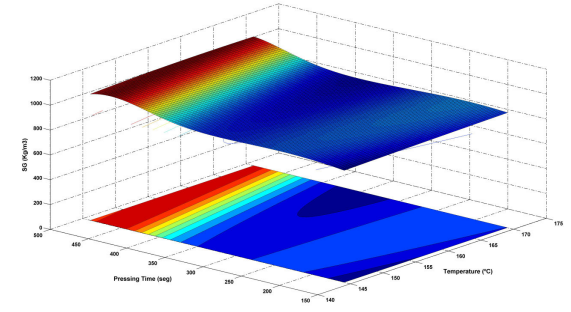

Figure 3: Specific gravity modeling in a particle board by means of temperature and pressing time.

These new tools will allow modern forest companies to adapt in very a flexible and cost-effective way to their market requirements. 
Citation: Fernández FG, Izquierdo S (2016) The Use of Artificial Intelligence in Forest Product Manufacturing: A Low-cost Improvement in Competitiveness. Ind Eng Manage 5: e132. doi:10.4172/2169-0316.1000e132

Page 2 of 2

\section{References}

1. AENOR (2002) Wood-based panels - Determination of moisture resistance under cyclic test conditions.

2. Cook DF, Chiu CC (1997) Predicting the internal bond strength of particleboard, utilizing a radial basis function neural network. Engineering Applications of Artificial Intelligence 10: 171-177.

3. Sukthomya W, Tannock J (2005) The training of neural networks to mode manufacturing processes. Journal of Intelligent Manufacturing 16: 39-51.

4. Khosravi A, Nahavandi S, Creigton D, Atiya AF (2011) Comprehensive review of neural network-based prediction intervals and new advances. IEEE Transaction in Neural Networks 22: 1341-1356.

5. Efron B, Tibshirani RJ (1993) An introduction to the bootstrap. Chapman and Hall, CRC Press, London.
6. JCGM (2008) Evaluation of measurement data-Supplement 1 to the Guide to the expression of uncertainty in measurement-Propagation of distributions using a Monte Carlo method. (1stedn), Geneva.

7. Mazloumi E, Rose G, Currie G, Moridpour S (2011) Prediction intervals to account for uncertainties in neural network predictions: Methodology and application in bus travel time prediction. Engineering Applications of Artificial Intelligence 24: 534-542.

8. Arhami M, Kamali N, Rajabi MM (2013) Predicting hourly air pollutant levels using artificial neural networks coupled with uncertainty analysis by Monte Carlo simulations. Environmental Science and Pollution Research 20: 4777-4789. 